ISBN / 978-93-5137-179-3

ISSN

$2320-7329$

Ayurlog: National Journal of Reseach in Ayurved Science

\title{
Role of Raktamokshana by Jalaukavacharana in the management of Vicharchika (Eczema)
}

\author{
Sidhesh Mehta* ${ }^{1}$, B. N. Deshpande ${ }^{2}$
}

1. M. S. Scholar $\left(2^{\text {nd }} \mathrm{Yr}\right)$

2. Guide and HOD

Shalya Tantra Dept., CARC, Akurdi, Pune, Maharashtra

*Corresponding Author: siddheshmehta@gmail.com

\section{Abstract:}

Out of 11 Kshudrakustha, Vicharchikaranks in the topper striatum. The sign and symptom of Vicharchika as expounded in classical text are almost analogous to dermatitis (eczema). As far as eczema is concerned it is a known - contagious inflammation characterized uniquely by erythema scaling, oedema, vesaculation and oozing.

Raktamokshana is a process by which the blood is let out from the body for eliminating vitiated dosha present in blood as a part of achieving therapeutic effect. This is envisaged to be removing impurities of blood and enhancing the haemopoesis. Though various methods had been in practice, yet Jalaukavacharana is proven to be the apt one for rendering Raktamokshana.

A clinical study has been carried out to ascertain the role of Raktamokshana in the management of Vicharchika.

Significant results pertinent to the parameter like Kandu, Pidika, Shyava, Bahusrava etc. were observed.

Critical analysis of the result will be presented in the full paper, on the basis of available results on explanation regarding mode of action of Jalaukavacharana in eczema will be also discussed.

KEYWORD: Vicharchika, Jalaukavacharana, Eczema. 


\section{INTRODUTION:}

Any disease that involves skin hampers many functions and gives the person a hideous look. As skin diseases are perceptible to others, they are more painful for the patient and troublesome for the physician. Several skin diseases affect the person's psychological status and disturb the social life, thus patient have some kind of inferiority complex; eczema is one among them. In Ayurveda, skin diseases are explained under the common terminology "Kushtha" which implies exposed diseases. Eczema is a skin disorder characterized by itching erythema, scaling, edema, vesiculation, and oozing. The involvement of Vata results in dry or blackish lesion of eczema. However, itching in those affected areas is due to Kapha.[1] Modern medical science treats eczema with corticosteroids. But the therapy gives side effects like liver and kidney failure, bone marrow depletion, etc. The texts of Ayurveda consider RaktaDusti as one of the prime causes of skin diseases;[2] on the other hand, patients may get relief after letting out the vitiated Rakta. AcharyaSushruta propounds practical guidelines for bloodletting and claims it as most effective therapy in half of the body ailments.[3] Among various methods for bloodletting[4]

such

as JalaukavacharanaKarma,Prachhanna

Karma,[5] and Siravedhana

Karma.[4] Jalaukaavacharna Karma[6] (Leech therapy) is considered as the ideal method to expel out the vitiated blood safely, quickly, and effectively. So, Jalaukavacharanais considered to evaluate their comparative efficacy in cases ofVicharchika (Eczema).

\section{Aims and Objectives}

To assess clinical effect of Jalaukavacharanain the management of "Vicharchika."

\section{Materials and Methods}

Patients attending the O.P.D. and I.P.D. of Shalyatantradepartment CARC akurdi, pune having classical signs and symptoms of Vicharchika (Eczema) were selected irrespective of religion, sex, occupation, etc. The study was approved by Institutional Ethics Committee. A special Proforma including all the etiological factors

of Kushtha with DushtiLakshana of Dosh, Dushya, Srotas, etc., was prepared for proper assessment.

Inclusion criteria

Patients having signs and symptoms of Vicharchika (Eczema) described in 
classical Ayurvedic texts as well as in Modern Medical literature; patients above 16 years and below 70 years of age; and chronicity not more than 5 years were included.

\section{Exclusion criteria}

The patients less than 16 years and above 70 years of age were excluded. Patients suffering from diseases like anemia, hemorrhagic disorders, diabetes mellitus, cancer, tuberculosis, hemiplegia, convulsions, and other severe complicated systemic disorders were excluded. Wounded, timid, thin patients, pregnancy, and chronicity more than 5 years were also excluded.

\section{Criteria of assessment}

Total effect of therapy was assessed considering following criteria:

Cured: $100 \%$ relief in the signs and symptoms with plain skin surface.Significant changes in color of the affected skin lesion toward normal was considered as cured. Marked improvement 76 to $99 \%$ relief in the signs and symptoms were recorded as complete remission with marked improvement in pigmentation and thickening of the skin. Moderate improvement: 51 to $75 \%$ relief in signs and symptoms were considered as moderately improved with moderate improvement in pigmentation and thickening of the skin. Mild improvement: Patients showing improvement in between 26 and 50\% in signs and symptoms with slight improvement of pigmentation and thickening of the skin was taken as mild improvement. Unchanged: Below 25\% relief in signs and symptoms was considered as unchanged.

All the patients were examined weekly during the treatment. Assessment was done on the basis of relief in the signs and symptoms of the disease Vicharchika. For this purpose, cardinal signs and symptoms were given scores according to their severity before and after the treatment.

\section{Pathological investigation}

Routine hematological investigations like hemoglobin, total count, differential count, erythrocyte sedimentation rate (ESR), bleeding time (BT), clotting time (CT), and urine examination were done to rule out any other disease pathology as well as to evaluate safety and efficacy of the trial therapy.

\section{Sampling}

Total 30 patients of Vicharchika (eczema) were registered for the present study. Four sittings of Jalaukavacharana Karma were carried out in consecutive four weeks. Number of Jalauka applied was decided 
on the basis of the size of lesion (example, $1 \mathrm{~cm}=1$ leech). Out of total 30 patients only 2patient discontinued course of treatment.

\section{Procedure}

Jalaukavacharan karma was done after local abhyanga and swedan on the effected part of the body. But was discontinued on the day before and on the day of JalaukavacharanThere were four sitting of Jalaukavacharana in one month with gap of seven days.Jalauka, three water bowl, cotton, bandage, turmeric powder and paper tap were used for this process.

\section{Pathya-Apathya}

Pathya-Apathya was advised to the patient as per classics.

\section{Observations}

Maximum numbers of patients, (24.14\%), were of the age group 21 to 30 years, $41.38 \%$ were housewives and $86.21 \%$ were habituated to vegetarian diet. Maximum numbers of patients, $(62.07 \%)$, were having regular bowel habit, and $100 \%$ were having Madhura and Amla Rasa dominancy in their diet. The $82.76 \%$ were having dietary pattern of Visamashana and $\quad 68.96 \% \quad$ were addicted to Tea. Maximum, (51.72\%), patients were having Pitta-KaphaPrakriti. Maximum numbers of patients, (100\%), were taking ViruddhaAhara (milk

+ Khichadi, New Annasevana, and excess intake of salt). Chinta (Stress) was reported in maximum, $(40.70 \%)$, of patients. The $17.24 \%$ of patients were having contact irritant with rubber.

In the present study, Kandu was observed in maximum $(96.55 \%)$ number of patients. Signs and symptoms like Vaivarnya (discoloration), Raji (lichen ification), Raktima (redness), and Rukshata (dryness) were observed in $93.10 \%, 72.41 \%, 68.96 \%$, and $58.62 \%$ of patients, respectively. Pidika (boil) and Daha(burning) were observed in $65.52 \%$ of the patients. Symptoms like Srava (discharge)

(37.93\%), Shotha(inflammation)

(24.14\%), and Ruja (pain) (17.24\%) were observed in some of the patients. The $93.10 \%$ of patients were having gradual onset, while $72.41 \%$ of the patients were having chronic course of the disease. The $68.96 \%$ of the patients were having Sushka (dry) type of Eczema.

In winter season, aggravation was observed in $24.14 \%$ of the patients. The $51.72 \%$ of the patients were having lesion size 5 to $10 \mathrm{~cm}$. On maximum, $46.67 \%$, patients, average 11 to 15 number of Jalauka were applied during full course of treatment. During four sittings in 15 patients' treatment, maximum 
47.50\%Jalauka sucked the blood for average 30 to 35 minutes. Average sucking time for Jalauka was found to be 20 minutes.

\section{Results}

Effect of therapy on laboratory parameter is depicted at Table. All the changes were statistically

insignificant.Jalaukavacharana showed highly significant increase in CT [Leech saliva contains anticoagulant substance like hirudin, calin, and destabilase, which increase bleeding time and clotting time during course of therap.[]

Effect of therapy on chief complaint after Jalaukavacharana

Karma:

Percentage-wise improvement was observed in signs and symptoms like Kandu (23.26\%), Pidika (66.67\%), Ra ktima (53.23\%), and Daha (80\%) which was statistically highly significant $(P<0.001)$. Statistically significant $(P<0.01)$ improvement was observed in signs and symptoms like Srava (77.78\%), Vaivarnya (27.27\%), and Rukshata $(21.74 \%)$. Signs $\quad$ and symptoms

like Raji $(P<0.05)$, Shotha $(P<0.05)$, and Ruja $(P<0.10) \quad$ were $\quad$ improved percentage wise $(28.57 \%, 80 \%$, and $33.33 \%$, respectively), but it was statistically insignificant [

\section{Total effect of therapy}

No patient was completely cured, whereas $21.43 \%$ and $50 \%$ of patients got marked improvement and mild improvement, respectively. Remaining $28.57 \%$ patients were having little change in their symptomatology.

$\underline{\text { Table }}$

Overall effect of Leech therapy

\begin{tabular}{|l|c|c|}
\hline & Jalaukavacharana & $\%$ \\
\hline Cured & 0 & 0 \\
\hline $\begin{array}{l}\text { Marked } \\
\text { Improvement }\end{array}$ & 0 & 0 \\
\hline $\begin{array}{l}\text { Moderate } \\
\text { Improvement }\end{array}$ & 3 & 21.42 \\
\hline $\begin{array}{l}\text { Mild } \\
\text { Improvement }\end{array}$ & 7 & 50 \\
\hline Unchanged & 4 & 28.57 \\
\hline
\end{tabular}

\section{Discussion:}

Majority of the patients belonged to age group of 21 to 30 years (24.14\%). This age of individuals are prone to psychological stress and other exposure, (occupational, environmental, and unwholesome food were more) which are etiological factors for eczema. Maximum number of patients, (41.38\%), were housewives, followed by $37.93 \%$ patients who were businessmen. This reflects that housewives are more exposed to household appliances, related to dust, and detergents, etc., which are 
common causative factors forVicharchika.

Servicemen like teachers and engineers who are having job with continuous standing may be prone to stasis to eczema.

The $27.59 \%$ of patients were having Chinta. Emotional conflicts are among main etiological factor for skin manifestation. Eczema may become more aggressive in this state.[8] ViruddhaAhara (incompatible diet), (milk + Khichadi, fast food, curd, non-vegetarian diet) and sleep during day time which leads to vitiation of Kapha and Rakta.

These

vitiated Doshas reach

to Dushya like Twaka, etc., and results into SthanaSanshrayaAvastha and then produces symptoms of Vicharchika.

Most of the time, at the biting and during entire Jalaukavacharana process, patients did not experience any discomfort, but in rare case, patients felt like pricking pain, itch on the affected lesion, and numbness of lower limb due to long-lasting sitting in one posture. Two patients of 14 reported itching all over body after the completion of leech application. Maximum patients reported feeling of little hardness of skin at the site ofJalauka bite, which subsided after 20 to 25 days without any mark left at that site.
Effect of therapy after Jalaukavacharana Karma on chief complaints

Kandu (itching) was relieved in $23.26 \%$. Kandu is caused by vitiatedKapha,[9] Pitta,[10] and Vata.[11] So, here, Tridosha vitiation is responsible for it. Relief in Kandu may be due to expelling out of vitiated morbid Dosha (toxins) from local region. Leech salivary secretions also provide early healing effect by secondary hemorrhage which might have reduced itch impulse.[12]

On Pidika (Carbuncle), $66.67 \%$ relief was observed. Leeches are antiphlogistic, used for the local obstruction of the blood. Due to this reason, Pidika might have subsided. Congested blood is also removed from the local area by leech; so, better relief in Pidika might have been provided by Jalaukavacharana.

Srava (discharge) was relieved in 77.78\%. Ushna and TikshnaGuna of vitiated Pitta are responsible for Srava. Siravedhana corrects the vitiation of Pitta better in comparison with Jalaukavacharana, hence reduces the Srava on the local lesions level.

Vaivarnya (discoloration) was relieved in 27.274\%. Jalaukaremoves impure blood and allows oxygenated blood to enter the 
wound area, which might have provided better color to skin.

Raktima (redness) was relieved up to $53.23 \%$. Leech saliva contains antiinflammatory substances, eglins and bdellins, which may relieve redness of lesion.

On the Daha (burning), $80 \%$ relief was observed. Leech saliva contains histaminelike substances and acetylcholine which is vasodilator and removes local inflammation mediators, thus relieve burning sensation of lesion.

The $28.57 \%$ relief was observed in Raji (lichenification) due to better removal of impure and congested blood by effect of hirudin, calin, destabilase, and Factor Xa inhibitor.

Shotha (Edema) was relieved up to $80 \%$ due to reduction of local pressure by substance like eglins and bdellins present in leech saliva.

The $33.33 \%$ relief was observed inRuja (pain). Leech saliva contains anesthetic substance which helps in pain relive.

$\mathrm{Hb}$ decreased by $1.81 \%$. Leech therapy is always associated with a certain degree of blood loss, which is clinically irrelevant in most cases.
CT was increase in $6.27 \%$.Leech saliva contains anticoagulant substance like hirudin, calin, and destabilase, which increase bleeding time and clotting time during course of therapy.

\section{Conclusion}

Jalaukavacharana

Karma provides

statistically high significance $(P<0.001)$ in the symptoms of Vicharchikalike Kandu, Pidika, Raktima, and Daha. Leech saliva is reported to have many therapeutic contents like hirudin, bdellins, Hyaluronidase, etc.; among them, eglins and bdellins have antiinflammatory and antifungal property which gives relief in symptoms of Vicharchika. In present study, "Jalaukavacharana Karma" proved to be effective in the management of Vicharchika. Jalaukavacharana is safest and scientific method among Raktamokshana.

\section{References:}

1. Parikha Rasiklala J., editor. Madhava, Madhava Nidana with Madhukosha, Kushthanidana, Adhyaya.Vol. 49. Ahmadabad: SastusahityaVardhaka Karyalaya; 2003. p. 23.

2. AacharyaVaidyaJadavajiTrikamji., editor. Vol. 24. Varanasi: Chaukhamba Sanskrit Sansthan; 1990. Charaka, 
Charakasamhita

Sutrasthana,

Nov

10].

Available

VidhishonitiyaAdhyaya; p. 12.

3. AacharyaVaidya Jadavaji Trikamji, Acharya Narayana Ram., editors. 2nd ed. Vol. 8. Varanasi: Chaukhamba Surbharti Prakashan; 1990. Susruta, Susrutasamhita, Sutrasthana, Shastravacharniya Adhyaya; p. 23.

4. Ibidem Susruta Samhita. Sutra Sthana Jalaukavacharniya Adhyaya. 13:4.

5. Ibidem Susruta Samhita. Sutra Sthana Jalaukavacharniya Adhyaya. 13:40.

6. Ibidem Susruta Samhita. Sutra Sthana Shonitavarnaniya Adhyaya. 14:24.

7. Niagara Medical Leeches (Verbana LLC) (c) 2005-2010. [Last accessed on 2011 Mar 01]. Available from: http://www.leeches.biz/

8. Auckland allergy Clinic Eczema. [Last updated on 2010 Jan 16; cited on 2002 from:http://www.allergyclinic.co.nz/guides /13.html .

9. Aacharya Vaidya Jadavaji Trikamji., editor. 2nd ed. Vol. 20. Varanasi: Chaukhamba Sanskrit Sansthan; 1990. Charaka, Charakasamhita, Sutrasthana, Maharoga Adhyaya; p. 18.

10. Ibidem Charaka Samhita. Sutrasthana Maharoga Adhyaya. 20:15.

11. Vol. 1. Mumbai: Nirnaya Sagar; 2006. Sharangadhara, Sharamgdhara samhita Purvakhanda, Rogaganna Adhyaya; p. 114.

12. Farming Medicinal Leeches. [Last updated on 2010 Feb 16; cited on 2002 Aug 05]. Available from:http://www. leeches.biz/

\section{Cite this article:}

Role of Raktamokshana by Jalaukavacharana in the management of Vicharchika (Eczema) Sidhesh Mehta, B. N. Deshpande

Ayurlog: National Journal of Research in Ayurved $S_{\text {cience-2018; 6(1): 1-8 }}$ 